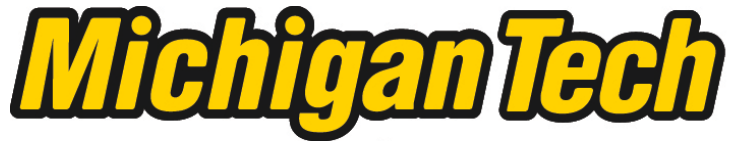 \\ Michigan Technological University Create the Future Digital Commons @ Michigan Tech
}

Dissertations, Master's Theses and Master's Reports - Open

Dissertations, Master's Theses and Master's

Reports

2011

\section{Analysis of the Making Our Mark project}

Shaughn Kern

Michigan Technological University

Follow this and additional works at: https://digitalcommons.mtu.edu/etds

Part of the Rhetoric and Composition Commons

Copyright 2011 Shaughn Kern

\section{Recommended Citation}

Kern, Shaughn, "Analysis of the Making Our Mark project", Master's report, Michigan Technological University, 2011.

https://doi.org/10.37099/mtu.dc.etds/543

Follow this and additional works at: https://digitalcommons.mtu.edu/etds

Part of the Rhetoric and Composition Commons 
AN ANALYSIS OF THE MAKING OUR MARK PROJECT

Shaughn Kern

\begin{abstract}
A REPORT
Submitted in partial fulfillment of the requirements for the degree of MASTER OF SCIENCE

in Rhetoric and Technical Communication
\end{abstract}

MICHIGAN TECHNOLOGICAL UNIVERSITY

2011 
This report, "An Analysis of the Making Our Mark project," is hereby approved in partial fulfillment of the requirements for the Degree of MASTER OF SCIENCE IN RHETORIC AND TECHNICAL COMMUNICATION.

Humanities

Signatures:

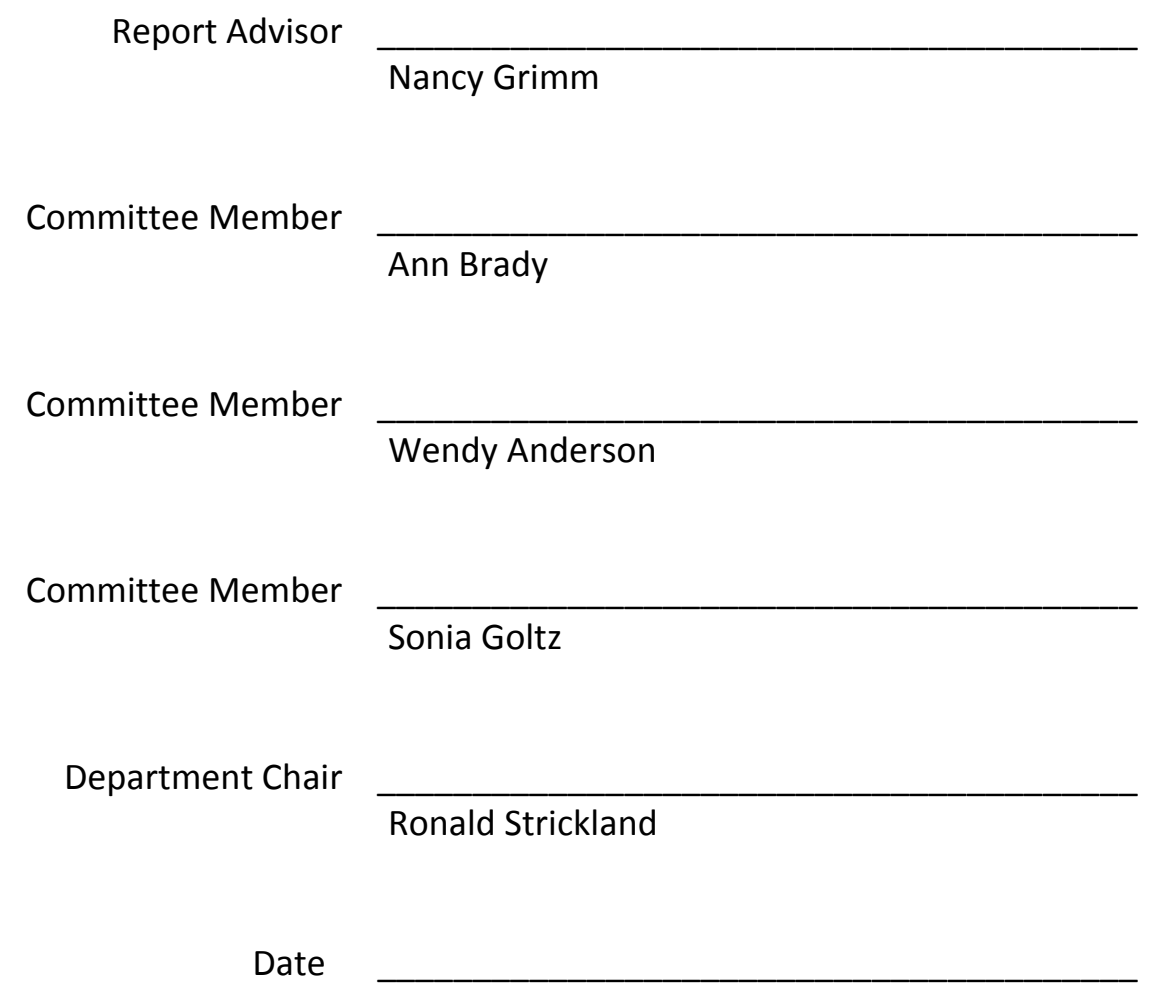




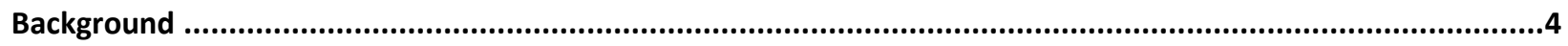

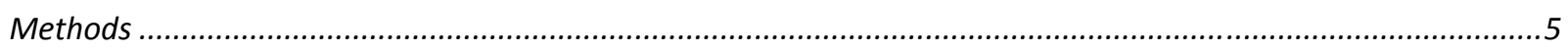

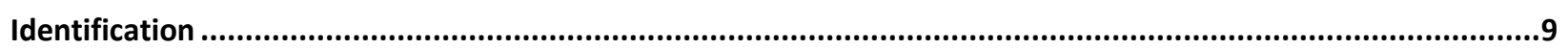

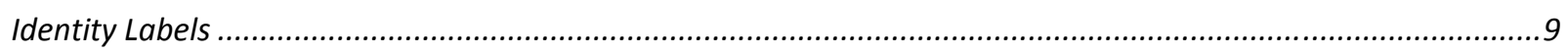

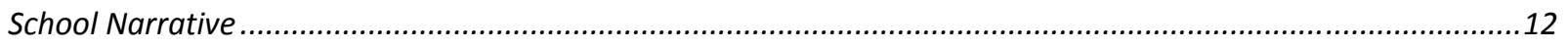

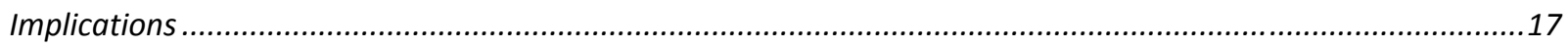

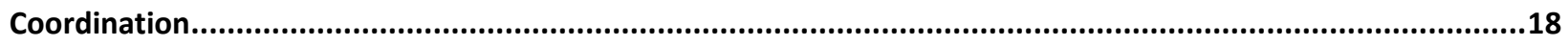

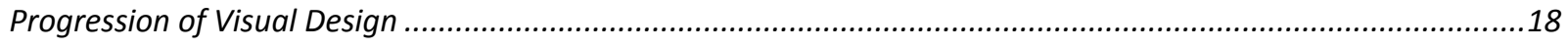

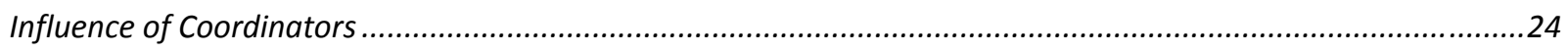

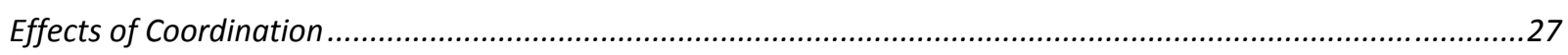

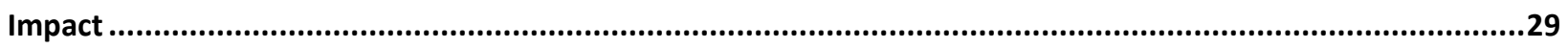

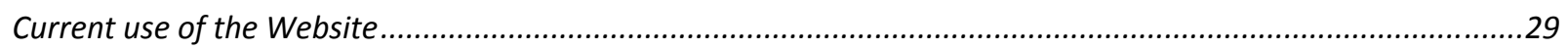

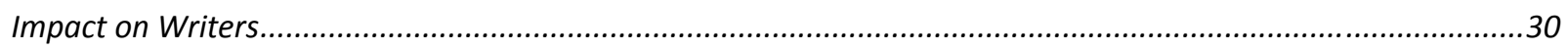

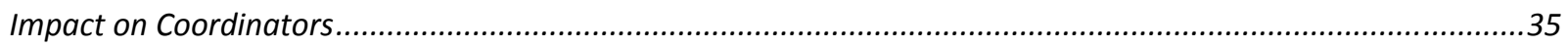

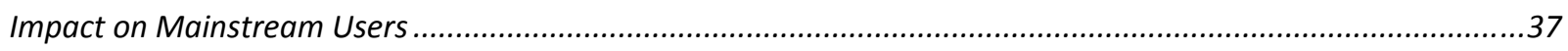

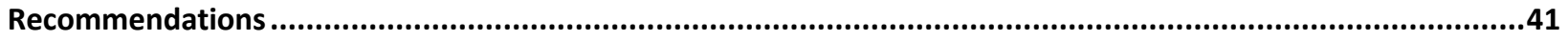

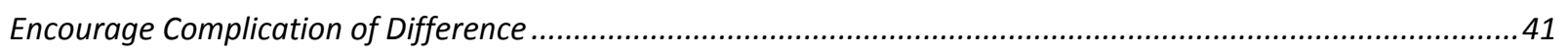

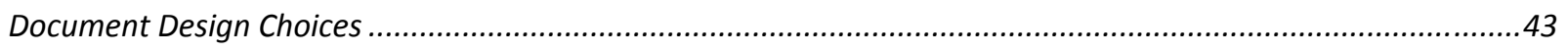

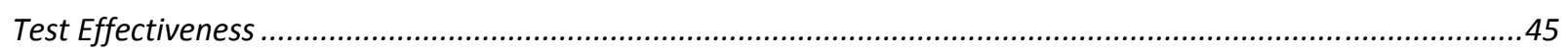

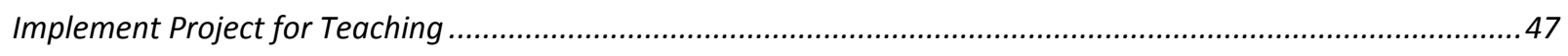

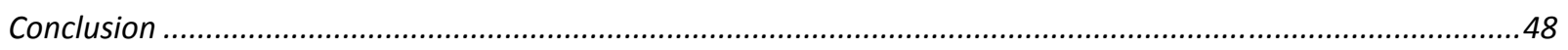

References......................................................................................................................................49 


\section{Background}

Making Our Mark is a series of narrative web pages created annually by students and coordinators at Michigan Technological University. It began in 2001 when PhD student Nancy Barron noticed, during her dissertation research, that several students from traditionally underrepresented backgrounds ${ }^{1}$ had experienced similar challenges while navigating the university setting, and had found solidarity and strength in the stories of others who had encountered difficulties from being at a university with a rather homogenous student body (Barron, Valentine). Subsequently, Making Our Mark emerged as a program to publish a collection of these stories and struggles into websites. It is funded through Michigan Tech's Department of Educational Opportunity by a grant from the King-Chavez-Park Initiative, and coordinated by the Michigan Tech Multiliteracies Center (MTMC) ${ }^{2}$. The theoretical basis of Making Our Mark is the creation of "productive diversity" (pluralism) as defined in Multiliteracies: "the idea that what seems to be a problem - the multiplicity of cultures, experiences, ways of making meaning, and ways of thinking - can be harnessed as an asset" (New London Group 13, Making Our Mark). Therefore, the goal of Making Our Mark is to present personal and realistic experiences of students from nonmainstream demographics. Accordingly, the practical aim is to provide support for students, while also changing the way in which people perceive difference; rather than being an obstacle that needs to be overcome, difference should be seen as something that positively contributes to our institutions.

\footnotetext{
${ }^{1}$ Specifically, this refers to students who have combinations of gender, class, race, ethnicity, sexuality, and age that are not commonly represented at Michigan Tech .

${ }^{2}$ The MTMC was formerly known as the Michigan Tech Writing Center.
} 
Making Our Mark is maintained by a rotating group of coordinators - graduate students from Michigan Tech's Rhetoric and Technical Communication program - who work to organize the process of generating the narratives that comprise the project. After contacting potential authors, the coordinators set up a number of meetings. These allow for the writers to meet with each other, find out about the background of the project, and work with coaches in the Michigan Tech Multiliteracies Center to brainstorm both written and visual aspects of the narrative. Since the writers are undergraduate students with very busy schedules, the coaches provide support throughout the composition process so that it is easier for the writers to create their narratives. One of the more tangible duties of a coordinator, however, is to code and integrate the narratives into a functional web site. Currently, the coordinators encourage the writers to creatively design how their narrative will function as a multimodal text; while the writers may not write multimodally by default, the aforementioned meetings provide support for this approach by organizing workshops for both written and visual designs, and encouraging writers to use any combination of media that they feel comfortable with. Meanwhile, if the writers were to code their own web sites, there would be many more constraints imposed on their artistic visions. The time needed to learn and execute web design is not always feasible for students taking a full load of coursework. Ideally, the graduate students act as facilitators and coordinators rather than a teacher trying to push an agenda. So, while the coordinators do inevitably shape the process of creating the website, their goal is to provide a helpful context in which the writers can compose their narratives.

\section{Methods}

Ten years and 64 stories later, Making Our Mark merits examination to determine if a "mark" is being made. I begin by examining related scholarship of previous coordinators of Making Our Mark in order to make explicit the purpose and history of the project. The sources for this examination include 
the PhD dissertations of Nancy Barron, Kathryn Valentine, and Karen Springsteen (2001, 2003, and 2008 respectively), as well as Jill Hodges's master's coursework paper (2005). I also look for specific concerns and problems expressed by the former coordinators, and compare these with my own experience as a coordinator. Aside from drawing on the research done on Making Our Mark by previous coordinators, I also undertake my own textual and visual analysis of the narratives themselves. ${ }^{3}$ Specifically I examine common themes in narrative structure, positive and negative discussions of difference, and identification of the authors as "active participants in social change" (Cope and Kalantzis 7).

In Multiliteracies, the New London Group argues that institutions have shifted from "exclusion and assimilation" to "superficial multiculturalism," and proposes that education should instead shift towards a pluralism which allows for non-mainstream identities to exist without being overwritten by "the language of the dominant culture" (13-19). In the case of Making Our Mark, the specific type of pluralism is productive diversity, specifically the creation of "change and improvement" and "social mobility" within learning institutions (Kalantzis and Cope 121). I frequently refer back to Kalantzis and Cope's framework of the "four archetypical forms of modern education," as taken from Multiliteracies (123-124):

- exclusion: difference is not tolerated

- assimilation: difference is tolerated until it is erased by "crossing over"

- multiculturalism: varying lifeworlds accepted, but certain backgrounds are privileged

- pluralism: mainstream is transformed to provide for "same kinds" of opportunities for lifeworlds These forms are arranged within the realms of Work, Civics, and Private, as outlined in Table 1:

\footnotetext{
${ }^{3}$ Previous narratives (going back to 2002) are still accessible through links on the most current year's page.
} 


\begin{tabular}{|c|c|c|c|}
\hline & From & To & (proposed) To \\
\hline Education & Exclusion or Assimilation & Superficial Multiculturalism & Pluralism \\
\hline Work & Fordism & PostFordism & Productive Diversity \\
\hline Civics & Nationalism & Decline of civic & Civic Pluralism \\
\hline Private & Mass culture & Fragmented community & \multirow{2}{*}{ Multilayered Identities } \\
\hline
\end{tabular}

Table 1 - “Changing times and strategic possibilities” (148)

It is important to note that "productive diversity" is not the same as current institutional definitions of "diversity". Rather, the term "diversity" is commonly used in an inauthentic way to refer to a problem that needs to be solved, a benchmark that must be reached in order to "fix" difference. Kalantzis and Cope argue that this constitutes superficial multiculturalism rather than pluralism (16-18).

Examining these factors allows for the articulation of several ongoing and overlapping tensions present within the identification, coordination, and impact of Making Our Mark. My methods for investigating these tensions draw on recent discussions of Multiliteracies and technological access. According to Kalantzis and Cope, a pedagogy of Multiliteracies focuses on the "big picture" of literacy in different national and cultural contexts, where "disparities in educational outcomes" are the primary problems that need solving. Specifically, Multiliteracies engages literacy outside of "language only," and aims to address modes of representation in different contexts (3-5).

Since many of the "tensions" within Making Our Mark overlap with one-another, a strict categorization is difficult. However, for the purposes of this paper I have grouped the project's issues into three different categories for examination:

- Identification - The ways in which the writers represent themselves through their narratives

- Coordination - The ways in which the project is organized and influenced by the coordinators

- Impact - The ways in which the completed websites are affecting various audiences 
My rationale for the taxonomy of these categories is to showcase three main sections of the project's development: the creation of narrative by the authors in identifying themselves as nontraditional students; the shaping of the narratives by the coordinators in order to create a cohesive project and website; and, the actual effects on audiences inside and outside of Making Our Mark.

The following three sections of this paper illustrate the tensions within each category while connecting the issues to the abovementioned areas of scholarship. My analysis of these tensions focuses on answering two overarching questions: what factors impede and restrict productive diversity in Making Our Mark; and, based on these, what actions should be taken with the project? Accordingly, this report concludes by offering a set of recommendations for the future of the project. 


\section{Identification}

The first major area of tension to consider in Making Our Mark is identification - identification being the ways in which the writers represent themselves through their narratives. While each writer brings their own approaches to writing their narrative, and hence represent themselves in different ways, I focus on the major trends that have taken place throughout the project's history.

To begin, I examine changes in the use of "identity labels" within the narratives as one illustration of how the project changes over time, what tensions arise from these changes, and how these changes and tensions function in terms of Making Our Mark's goals. Next, I discuss some problematic trends in narrative style observed by previous coordinators of the project. I then examine how these trends apply to the narrative content of more recent years, and what these trends say about the identification within Making Our Mark's narratives. Finally, this section shows how the tensions illustrated by the (dis)use of identity labels and the frequency of "school narrative" build on each other to create a greater overall issue within Making Our Mark.

\section{Identity Labels}

The first feature of Making Our Mark I discuss takes place in the 2002-2005 narratives. I have chosen this particular range since these first four years were worked on by the same coordinator (Kathryn Valentine) and consequently have similar designs. Each page has an explicit, written identity of the writers: "Bryan - an African American Computer Science Student"; "Dan - a non-traditionally aged student majoring in Biology"; "Jill - a local English Ed major". These subtexts, which I refer to as "identity labels" were typically right next to the student's names or pictures on the home page, as shown in Figures $1 \& 2$. Consistently they refer to how exactly the writers are different, and what their major is. 


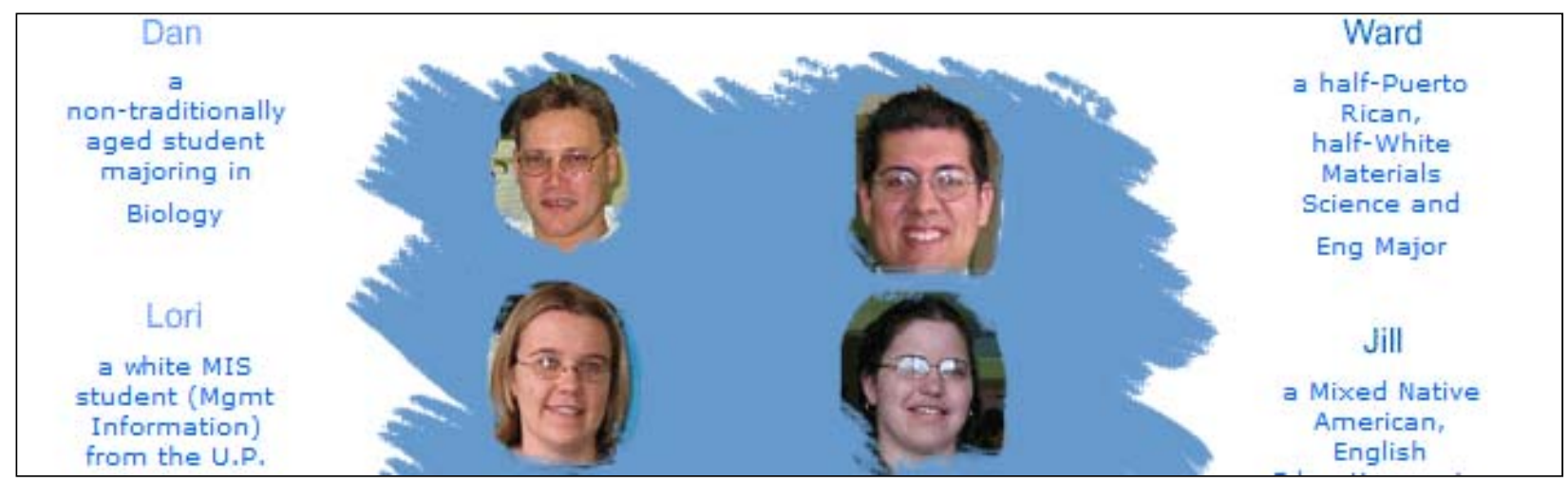

Figure 1 - Identity labels on the 2002 Making Our Mark homepage

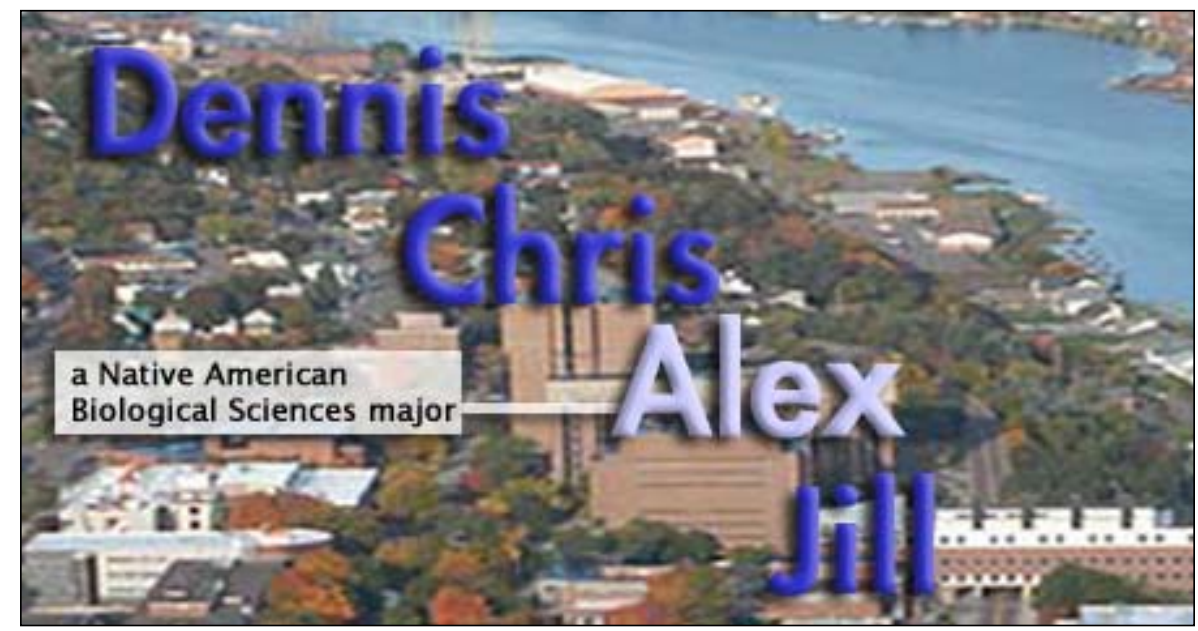

Figure 2 - A student's identity label on the 2005 Making Our Mark homepage

In her 2005 paper Hodges explains that the original reasoning for the labels was that they functioned as an "affirmation of their identity and...because other people think of the students in terms of their race" (20). The argument is that the label reflects the writers' "positioning within the institution," and that their identity is appropriately complicated by the written and visual aspects of the narrative. This explanation provides valuable insights into the nature of the project of the time. The danger with identity labels, to reference Sarah Michaels and Richard Sohmer, is the risk of inscription overtaking narrative. They describe inscription as the reduction of complexity to abstraction, that in turn leads to 
"lack of interrogation" and a "masking... of differentiating particulars" (Michaels 2000, 270-272, 284-

285). If the labeling in Making Our Mark reduces complexity and freezes definitions, it does not allow for the "generative, complexifying, multivoiced particularities" needed to avoid essentialization and tokenization, and hence interferes with Making Our Mark's goal of productive diversity (272).

Given Michaels and Sohmer's argument, one can see a rationale behind the choice to eventually drop identity labels from the project. The first step towards this occurred in 2006, when an author did not include a label in the title of her page (LaCasse 2006). A year later in 2007 there was a sudden shift to no longer using explicit labels for the writers (Figure 3). Oftentimes the written or visual narratives themselves showed some dimensions of difference, but the writers no longer included a one sentence declaration of identity.

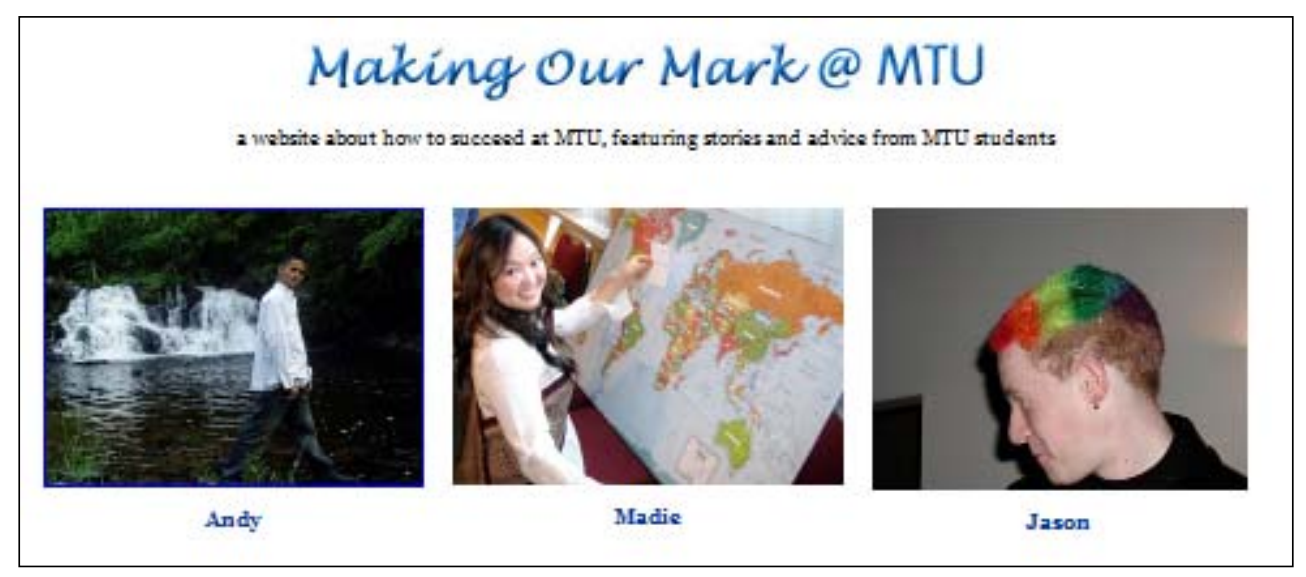

Figure 3 - Part of the 2007 Making Our Mark homepage

Since there is no longer a trend to "label" the authors at the beginning of the narratives, it is up to the writers to disclose their institutional positioning. The current narratives sometimes move in the direction of sidelining or ignoring difference altogether, with some 2008, 2009 and 2010 narratives containing almost no explicit mention of nonmainstream identities at all. This, coupled with visual design that sometimes omits pictures of the writer, removes one of the most important aspects of the 
project. Lack of difference in a narrative contributes to Making Our Mark in no way whatsoever. If the writers do not in some way mention how they are different from the mainstream, Making Our Mark becomes nothing more than the generalized web narratives published in other Michigan Tech web spaces. One narrative in particular (Hardy 2010) contains only a reference to growing up in Detroit. One might assume that the writer is African American, and they would indeed be correct. However, arriving at this assumption of the writer's identity is only done when a stereotype is invoked. On the other hand, a different student from the same year (Gregorakis 2010) does not explicitly label herself up front, but later in the narrative asks what "what groups on campus could a seventeen year old Hispanic female possibly fit into?" Looking at these two narratives, we can see that the lack of identity labels causes inconsistency in how the narratives portray the relation between struggle and difference.

Michaels and Sohmer call for a balance between inscription and narrative. If difference is just described by a label (inscription), the difference presented in Making Our Mark is nothing more than another diversity statistic to be counted and analyzed. On the other hand, if difference is only explained through personal experience (narrative), the audience is unable to understand where the students function within our institutional framework. Neither option achieves the level of dialogue needed for "sense making" on its own. Instead, the writers need to both "tell" and "show" their experiences.

\section{School Narrative}

The issue of labeling is closely tied to an overall trend of identification within the narratives: a large amount of the content's regulation and censorship of controversial issues is actually done by the writers themselves. There are numerous and significant instances where writers themselves restrict the authenticity of their content in favor of adopting what former coordinator Karen Springsteen refers to as "the persistent genre of school narrative" (Springsteen 128-135). Writers will begin with the struggles 
that they've encountered in college, discuss how they overcame those struggles, and recount a happy ending where all problems are resolved.

While Springsteen identified this problem in the narratives that were written up to 2006, future narratives continue - if not exacerbate - the trend of school narrative. One writer describes being excommunicated from her church due to her sexuality, before quickly jumping to a discussion of how much support Keweenaw Pride has offered (Anderson 2009). There is a problem, a move to Houghton, and seemingly without effort or incident everything is "solved". Others explain one dimension of difference in depth while sidelining another. The writer Talisha offers an in depth and emotionally potent narrative of becoming pregnant and having a child during college, which would give pause to any reader. On the other hand, a declaration that "it's very hard being the only African American in your class and/or not having anyone to study with on a regular basis" receives no treatment whatsoever (Sutton 2009). This could be a reluctance to talk about race, a decision that pregnancy was a more significant issue, a time constraint, or any combination of these and other factors. What remains is that this narrative, even being one of the most comprehensives narratives of the entire project, does not seem to have enough "space" to talk about complicated and multilayered identities in enough detail to complicate them.

These types of writing harshly parallel styles of narrative mentioned by a number of composition scholars. To begin with, Harvey Graff's "literacy myth" - the concept that literacy automatically and absolutely yields social and economic success - points to one possible explanation for the frequency of cleanly resolved stories. There is pressure on writers to treat academic journeys as ones that inevitably yield success. For example, one student (Redmond 2009) begins his narrative with his experience of being left out of lab groups because of his race, and finishes with a discussion of becoming "an 
enhanced version" of himself. These illustrations convey the very false idea that the problem of difference has been solved. Under Graff's "literacy myth," an education is a guarantee of success. For these students to not cleanly resolve their problems using school narrative would be to upset this narrative which is so ingrained in American educational culture.

Hesitance to confront matters such as sexism and racism is another possible reason for the persistence of school narrative. In his article "On the Rhetoric and Precedence of Racism" Victor Villanueva discusses the eagerness of participants in learning institutions to sideline discussions like racism. In their hopes to combat racism, schools treat racism as problem that has already been solved. A particularly strong illustration of this is when Villanueva presents the perspective of an administrator who perceives race as being something that can be "fixed" within a semester:

A meeting with that teacher and the principal. After explanations, I break into a lecture about racism. I do that. Often. From the Principal: "We had some problems with that at the beginning of the year, but we took care of them." And I want to know how he solved the problem of our nation "At the beginning of the year" (Villanueva 838).

A similar story takes place in Making Our Mark when a student describes that others "tend to forget how to speak English in my presence they simply assume that most black people commonly use slang as their primary language," but later on states that "I have been fortunate not to feel a lot of racial tension since I have been here" (Pew 2002) This is not necessarily a contradiction, as these quotes are juxtaposed from two different pages; however, this seems like an instance where racism is not actually called "racism," but is rather treated as a minor inconvenience that just comes with being different. It is expected by the members and administrators of our institution, according to Villanueva, that discussions of racism are silenced, either by the administration or by the students themselves. 
Other examples are not so much focused on resolving issues of identity so much as closing out discussions of difficult life events. This is similar to the previous example of avoiding discussions of racism, simply because the writer is censoring themselves on a subject that they feel is not appropriate to discuss. While writing on the passing of a family member, a writer named Sara showcases an abrupt transition in narrative.

I have never lost someone very close to me, and I really feel for those who do lose any of the people they care about. A few months later, his sister also passed away, my great aunt.

On a much lighter note, I got all four of my wisdom teeth removed during the school year. That was not fun (Goodell 2009).

This style is strongly reminiscent of Linda Brodkey's "Literacy Letters," where students enrolled in an Adult Basic Education (ABE) program corresponded with English teachers (681). For example, one writer discusses the respective murder and imprisonment of two people in her life, but then changes the topic. I don't know have must to siad this week a good frineds husband was kill satday at 3:15 the man who kill him is a good man her would give you the shirt off of his back...but anyway I see police academy three it was funny but not as good as the first two (685) According to Brodkey, the writer changes her tone because she feels that it is not appropriate to discuss an issue so tragic. The candidness of narratives is lost because of the invocation of a teacher/student relationship, where the audience (the teacher) represents institutional expectations of composition, and there is a potential risk for the writer if those expectations are violated or challenged. It could be said that Villanueva and Graff also attribute the pressure to write in school narrative to the power relationship between writers and institutional expectations. The one thing that is common in all of these 
examples there is a palatable moment where the writer decides that it is no longer acceptable to continue their story in the way they've been telling it, and they resort to a more familiar, comfortable, institutionally sanctioned format of narrative. If a Making Our Mark writer begins to tell their story and then defers to the genre of school narrative then a chance for productive diversity has been disrupted. If the writer resorts to a privileged style of narrative, the narrative is locked into superficial multiculturalism. Ultimately the power relationship plays a role in influencing school narrative.

It is important to note the difference between students who are abruptly censoring themselves versus those who are leaving problems unresolved. A student named Chee abruptly shifts the tone of his discussion of race issues in his final paragraphs:

My feelings of being a minority and different never went away.

I have though found a place here at Michigan Tech. I work in the Writing Center and have a close group of friends. I no longer feel uncomfortable when someone mispronounces my name during that first day of classes (Yang 2004).

While this is a shift from a "negative" discussion to a "positive" discussion, Chee is actually demonstrating that race isn't "overcome" in any sense. He has found a place in the university, although not because racism is no longer there. He has concluded his narrative on a positive note, but has not provided any sort of artificial closure for unresolved problems. Finally, he has achieved success, but not because it was the logical consequence of going to a university. By challenging and impacting mainstream conventions while still asserting the challenges that arise from being different, Chee is truly contributing to productive diversity. 


\section{Implications}

As we observe the progression and subsequent conflation of these two trends - the decline of discussions of difference, and the dominance of school narrative - we find that discussions of productive diversity in the narratives have become reduced in both quality and quantity.

Nearly all of the narratives contain at least one or two of the common complications of being a student at Michigan Tech: having a difficult academic load, not enjoying one's major, and being away from home. Ultimately the writers solve these problems by developing time management skills, finding themselves as a person, and joining student organizations, respectively. These are situations that happen to most of the students at the university, including those of mainstream backgrounds. While writing about more "mainstream" stories is not inherently bad, it combines with the lack of identity labels to supports the idea are post-race/gender/age/ethnicity/class/age.

The lack of difference in the narrative combines with the lack of difference in inscription to create a story that is entirely neutralized in terms of its ability to make a difference in the mainstream. There is no way to treat difference as an asset if there is no discussion of it, and the narratives created in Making Our Mark are no different from those of mainstream authors. This entirely defeats the purpose of Making Our Mark. In short, rather achieving productive diversity, this aspect of the project is at risk of regressing to assimilation. 


\section{Coordination}

As mentioned previously, the coordinators of Making Our Mark have a difficult balancing act to maintain. For example, Valentine explains the difficulty of avoiding "editing for correctness"; (169) it is not always easy for coordinators to know whether or not imperfect grammar is a mistake or a conscious departure from mainstream discourses. The coordinators of Making Our Mark are aware of this, so the writing of the Making Our Mark narratives is not regulated by the coordinators in terms of its content. To date, only one narrative of 64 has been removed by the coordinators, and this removal was done because of a request of the narrative's author (Making Our Mark 2000-2010).

It is important to consider that the last decade has seen innumerable changes to the way that websites are designed, and that one should not expect narratives from 2001 to look similar to narratives from $2010 .{ }^{4}$ There is nonetheless a distinct correlation between who was serving as a coordinator and the appearance of the website over time. This section illustrates the areas of Making Our Mark in which the coordinators make contributions to the design of the narratives.

\section{Progression of Visual Design}

To begin, I gauge how the evolution of visual design in the Making Our Mark website has contributed to productive diversity. The need to examine visual aspects of the narratives is that in a

\footnotetext{
${ }^{4}$ Many websites in the late 1990's-early 2000's were done with HTML or CSS coding, with little help from design programs. As web design software has advanced, and coding such as JavaScript and $\mathrm{PhP}$ has become more usable, there are more opportunities for novice web designers (i.e. the coordinators of Making Our Mark) to produce visually complex websites.
} 
Multiliteracies framework, "grammar" is seen as design choices, with design being "communication for specific ends...inherently connected to difference discourses based on wider interests and relationships of power" (The New London Group 27). The significance of this is that the visual designs of the narratives inform meaning as much as the linguistic design, and allows for a writer to present a wider range of discourses.

The first group of narratives I would like to examine spans from 2002 to 2004 , during the coordination of Katherine Valentine. While each narrative was presented as a separate section of the website, each narrative had an extremely standardized visual design in terms of color, layout, typography, etc., although there is little record of these choices (Making Our Mark, 2002, 2003, 2004). Two such stories, both from 2002, are shown in Figure 4; all other narratives for that year (and following years) follow the same visual format. While the designs on each year's homepage changes, the layout of the narratives themselves is exactly the same from 2002-2004.
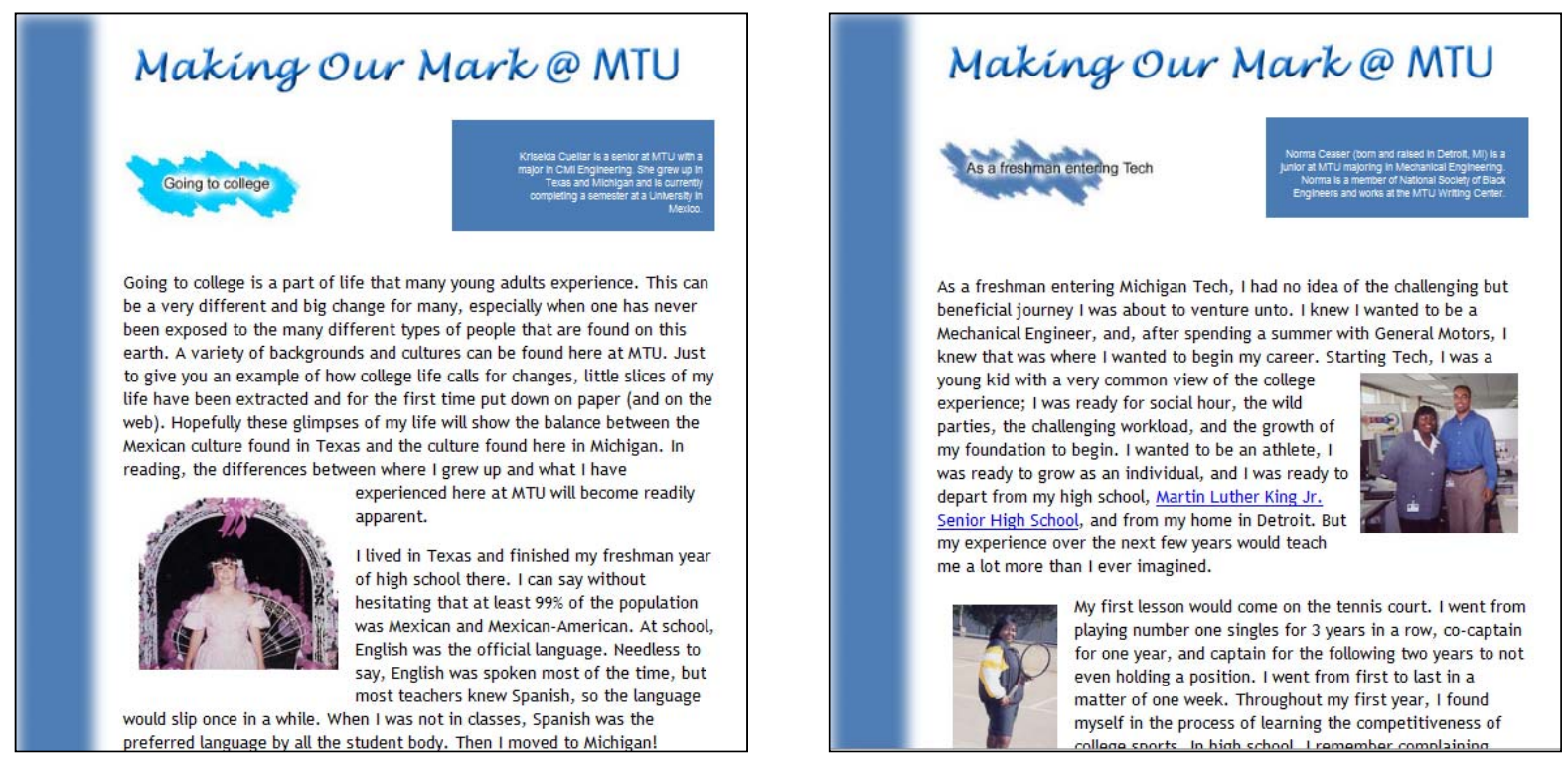

Figure 4 - Two stories from the 2002 website 
At this stage of Making Our Mark writers were allowed to upload pictures along with their narrative, but the contextual visual elements of each narrative remained the same. The visual format of the website was already been decided by the coordinator, so it is required that the writers' narratives fit into this format. Valentine, being the designer of these initial pages, "used the metaphor of a 'mark' visually in the frame, titles and page markers" according to her dissertation (145). Unfortunately, this design seems to no longer be in use on these pages, for reasons that have not been understood.

I would argue that restricting the style of narrative that the students can compose limits productive diversity. In terms of visual design, this approach lacks the "negotiated dialogue" for "participation, assess and creativity" required of the writers to achieve productive diversity (New London Group 13). In terms of web design, on the other hand, these early narratives made a much greater use of hypertext to link to websites outside of Making Our Mark. Table 2 below shows a year-byyear tally of how many students chose to include hyperlinks to outside webpages, and how many total hyperlinks were used.

\begin{tabular}{|c|c|c|c|c|c|c|c|c|c|c|c|}
\hline & 2001 & 2002 & 2003 & 2004 & 2005 & 2006 & 2007 & 2008 & 2009 & 2010 \\
\hline Students & & 5 & 5 & 7 & 2 & 1 & 2 & 1 & 0 & 0 \\
\hline Number & & 14 & 10 & 21 & 4 & 1 & 6 & 2 & 0 & 0 \\
\hline
\end{tabular}

Table 2 - Frequency of hyperlinks in Making Our Mark

While the text-heavy approach of early narratives tends to assimilate written narratives into a single visual style, the writers still have some room to extend their conversation beyond the walls of the website. So, the lack of control over visual design in this case does not completely limit productive diversity, but it does block some possibilities for it.

A number of significant changes were made between 2005 and 2008. The first notable change occurred in 2005 , when each author had contributed unique visual designs specific to their page. Figure 
5 shows a page where a Native American writer used eagle feathers along the left side of the page. The reader is expected to click on the feathers sequentially in order to navigate through the story.

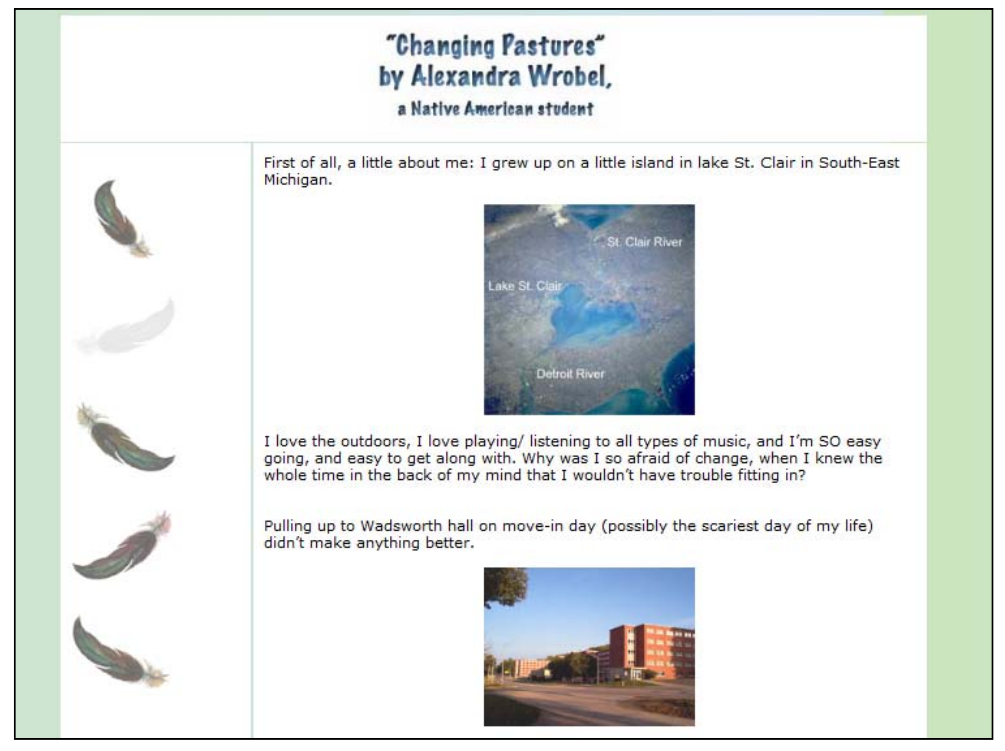

Figure 5 - A narrative from 2005 featuring the writer's design

In the case of this design, it is difficult to gauge why the writer made the design choice that they did.

From a mainstream perspective, this could be perceived as the author representing herself in terms of dominant institutional perceptions. Knowing nothing about the importance of the eagle feather in Native American and spirituality, it was difficult for me to see the significance of the image. However, this feather is not being used as simple decoration; it functions as the means by which to navigate the narrative.

These speculations aside, as the writers are given increased input on the design of their pages, they are taking their story beyond simply words, and able to demonstrate layers of difference and complexity purely through visuals. Figure 6 is a screenshot from the front page of a 2007 student's narrative. This student does not provide a linear or textual means of navigation, but rather shares meaningful images that, when clicked, take the reader to different sections of the story. 


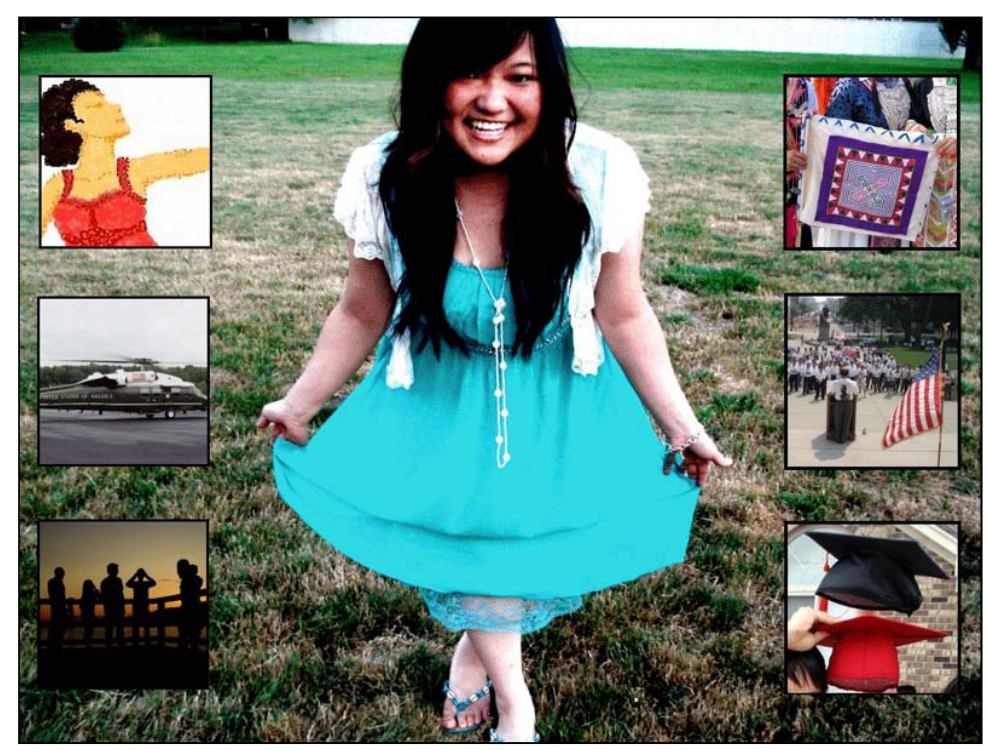

Figure 6 - The navigation page of a 2007 narrative

So, this level of visual design could fall somewhere on the spectrum between superficial multiculturalism and productive diversity, depending on the audience of the story and the reasons made for the design choice.

From the 2005 series of narratives onwards, all writers have customized their narrative's visual design in some way, oftentimes including imagery that directly ties into their identity and worldview. Ironically, in 2007 Michigan Tech began to increasingly standardize websites related to the university (University Marketing and Communications). Making Our Mark avoided this movement in that it is not classified as a Department Home Page, Department Resource Page, Student Organization Page, or other highly regulated genre of university website. This speaks, albeit indirectly, to Making Our Mark's ability to use personal narratives as a way of keeping the project's primary focus on the writers rather than the University.

The 2008 and 2009 narratives saw additional increase in sophistication of design, as writers began to work visual metaphors into more thematic narratives as a way of presenting other dimensions 
of identity. For example, a 2008 author (Sutton) builds her narrative around the metaphor of a board game (Figure 7). The readers navigate by rolling the dice and drawing cards. As the reader reads through the narrative, the game piece moves forwards and backwards towards its goal (graduation) as the cards of chance deal out scenarios such as making friends, having a baby, finding a balance, and studying.

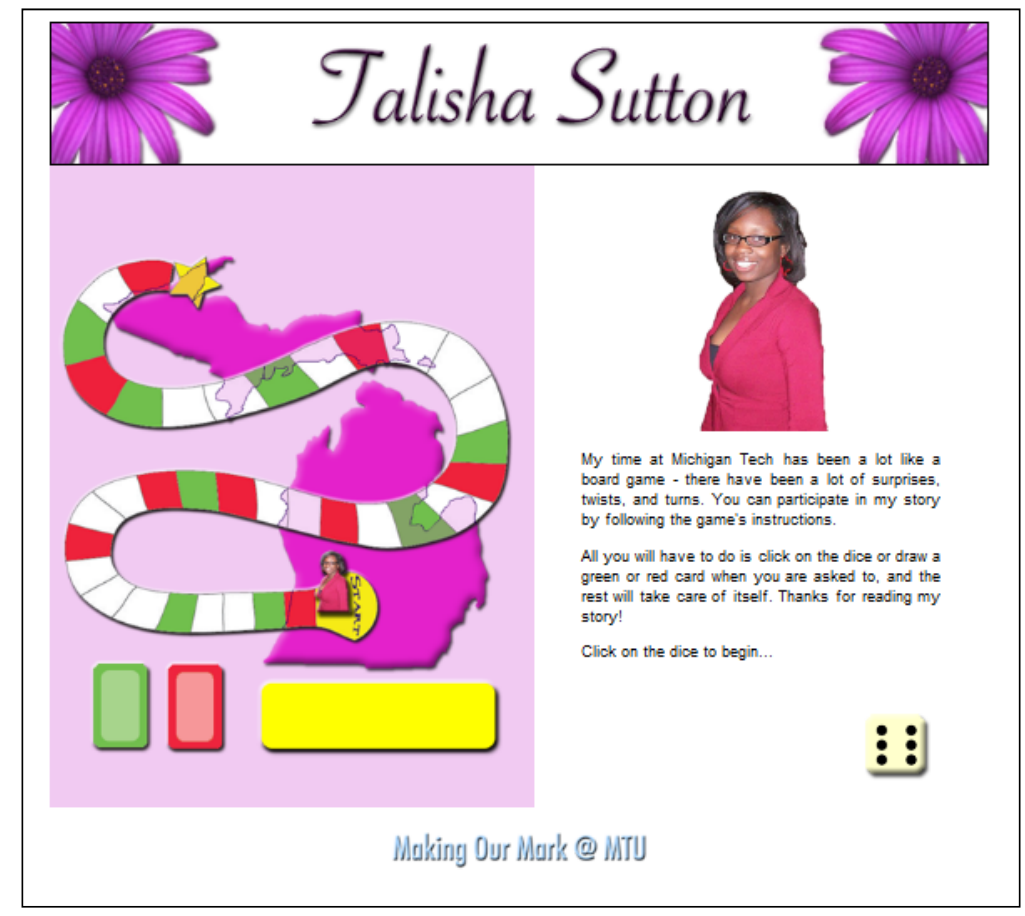

Figure 7 - A 2008 narrative with a thematic design based on a board game

This design is unique, personal, and engaging in a manner that the earliest websites were not. Rather than reduce herself to a few simple images, Talisha portrayed how she perceives herself in regards to her college experience, which is much different from how she might be positioned within/by the institution. Thus, the visual design of Making Our Mark has evolved over the years to represent dynamic, multilayered individuals, not statistics or labels.

Increased use of pictures, graphics, animations, colors, and various other visual effects increases the range of available designs for writers since there is no longer a mandated visual style that stories can 
be assimilated into (aside from the medium of the web browser itself). Giving more control of the web design to the students protects productive diversity in Making Our Mark in that writers are able to compose in a non-privileged discourse.

It is important to note though that increasing available designs does not automatically guarantee that productive diversity will trump superficial multiculturalism. A writer still has the option of conforming to privileged styles of visual design by composing with primarily text, or creating navigation that is more in keeping with traditional web design principles.

\section{Influence of Coordinators}

At this point it is worthwhile to note the periods of time during which each coordinator worked on Making Our Mark. Table 3 presents a timeline of changes in visual design, whereas Table 4 presents the period of time during which each coordinator served:

\begin{tabular}{|c|l|l|l|l|l|l|l|l|l|l|l|l|}
\hline Design Style & 2001 & 2002 & 2003 & 2004 & 2005 & 2006 & 2007 & & 2008 & 2009 & 2010 \\
\hline Standardized & & & & & & & & & & & & \\
\hline Unique & & & & & & & & & & & & \\
\hline Thematic & & & & & & & & & & & & \\
\hline
\end{tabular}

Table 3 - Timeline of visual changes in Making Our Mark 


\begin{tabular}{|c|l|l|l|l|l|l|l|l|l|l|l|l|}
\hline Coordinators & 2001 & 2002 & 2003 & 2004 & 2005 & 2006 & 2007 & 2008 & 2009 & 2010 \\
\hline Valentine & & & & & & & & & & & & \\
\hline Hodges & & & & & & & & & & & & \\
\hline Springsteen & & & & & & & & & & & & \\
\hline Carpenter & & & & & & & & & & & & \\
\hline Badke & & & & & & & & & & & \\
\hline Kern & & & & & & & & & & & \\
\hline
\end{tabular}

Table 4 - Timeline of coordinators for Making Our Mark

The years of the project that yielded the most significant changes in visual design -2005 and 2008 - are simultaneous with addition and changes of coordinators, respectively. In 2005 the Making Our Mark began to use "co-coordinators." Generally, one coordinator would be in charge of arranging meetings with writers, while the other coordinator actually coded the narratives into web pages. The addition of a second coordinator at this time was pivotal to managing the increased workload of more complicated web design.

In his article aptly titled "Multimodality," Günter Kress discusses the trend to "dislodge written language from the centrality" by incorporating wider ranges of media, particularly visual. One of the more significant uses of this, he argues, is to achieve "materiality" in the realm of communication in showing things that words themselves cannot (182-185). This relates to Making Our Mark quite explicitly, as the goal of productive diversity requires pluralism as opposed to a hierarchy of privileged and non-privileged statuses. If students are able to [a/e]ffectively share their stories in a way that is meaningful to them, and do so by using non-privileged forms of discourse, then productive diversity has been accomplished on two levels: that of the content of narrative itself, and that of the communicative style used to convey that narrative. The original narratives ranging from 2001-2004, while powerful in their content, disguised materiality by insisting that all narratives use the same combinations of 
modality. Kress would contrast this lack of design choices with multimodality, which can emphasize the materiality of a medium while simultaneously allowing for multiplicity of meanings (188).

This discussion of material conditions also extends to the ground level of how coordination functions in Making Our Mark. One of the arguments for the use of coordinators to code the websites is that that the writers, being college students, would have difficulty finding time to create the websites on top of writing the narratives and design. As multimodality has become more widely adopted and visual design has become more complicated, the coordinators play a much greater role in the project. An interesting concern related to this is presented in Samantha Blackmon's article “(Cyber)Conspiracy Theories". Blackmon argues that imbalances in literacy instruction extend beyond composition environments and into computerized environments. Nontraditional students, she argues, oftentimes come from backgrounds of "historically low access":

Although many African-American students now have the ability to do simple technological tasks such as word processing, many have no knowledge of things such as web-page building and publishing (157).

Blackmon argues that "material access" to computers must also be "competent, comfortable, and confident" in order to ensure equal access for those who "historically lack access to technology" (36).Since the point of Making Our Mark is to include narratives specifically from non-mainstream backgrounds, it is safe to say that not only would writers have difficulty finding time to create Making Our Mark without help from the coordinators; it's safe to say that many writers have experiences, perceptions or abilities that would complicate the process of creating the website. Simply put, this project could not happen without significant assitance from the coordinators. One question that inevitably arises over this concern is whether or not the writers are losing control over the project, or 
whether they are composing for a medium which favors mainstream representation of identities. These writers are indeed entering a privileged medium when they compose narrative websites, and this deeply entrenches the coordinator into the project. So, as the visual themes and metaphors become more and more sophisticated, and in turn move towards productive diversity, there is in turn a strengthening of the power difference between the coordinators and students.

\section{Effects of Coordination}

The evolution of Making Our Mark's design gives rise to the question of whether or not giving students more control over the visual elements of their website necessarily contributes to productive diversity. Karen Springsteen, the coordinator from 2005-2008, argues in her dissertation that the increased multimodality of Making Our Mark has not in itself guaranteed productive diversity. She argues that "...the power and persistence of school narrative overrode the potential that multimodality offered to create unconventional representations" (Springsteen 148). Ultimately, there has been an interesting tradeoff within the coordination of Making Our Mark between the increased freedom of design for writers and an increased role of the coordinators. On one hand, multimodality has allowed for a stronger representation of complex identities, therefore, the contribution of visual design contributes towards productive diversity. It is important to note that the productive diversity in visual design does not in itself solve any other issue relating to Making Our Mark, but is nonetheless an area of the project that has created more substantial possibilities of fulfilling the original goals of the project. On the other hand, it is clear that there has been an increased emphasis placed on the number and abilities of the coordinators because of this approach to design. While the coordinators have generally been very "hands-off" when it comes to the written narratives, coordinators nonetheless have a stong influence in the design of Making Our Mark. If the writers are composing for a medium that they might not perceive 
themselves as having full access to, this complicates the power relationship between them and the coordinators. As this relationship is invoked, there is increased likelihood that "school narrative" will occur. The material conditions of the website as a medium and the situatedness of the coordinators as gatekeepers could constitute superficial multiculturalism.

The numerous advantages and disadvantages of increased visual design in Making Our Mark's coordination do not simply increase the coordinator's responsibility in coding the website. It actually complicates the original job of the coordinator as an administrator and facilitator of the project. If the changes in coordination are not periodically benchmarked against the original macro-level goals of the project, the productive diversity actually created by Making Our Mark could very well be nullified by shortcomings in another area of the project. 


\section{Impact}

There is not a singular or definite audience for Making Our Mark (Valentine 144), but the founders of the project nonetheless had some intentions as to how the project would be used by numerous audiences. One of the very first intentions was for the narratives to function as points of solidarity for students that had experienced similar difficulties of being an underrepresented student at Michigan Tech, with the hopes that it would "support retention" among underrepresented groups. The second initial goal of the project was to "complicate (faculty and staff) understandings of students at Tech and that this might lead to changes in attitudes on campus" (Valentine 144). Springsteen mentions a secondary goal of "disrupting stereotypes and affirming difference" which reveals a third audience: users from traditional/mainstream backgrounds (Springsteen 30). Given the nature of productive diversity as necessarily having an effect on mainstream institutions, this audience must also be considered in terms of the use of Making Our Mark. Along with the current status of the website, these three audiences are examined in terms of how they might currently be impacted by Making Our Mark.

\section{Current use of the Website}

Determining the impact of the website on those outside of the project is also a difficult area to reflect on. The first batch of narratives (2002) was in fact user tested by first year students, and presented to various faculty and staff (Valentine 146). This provided excellent, direct feedback with regards to how one of the target audiences was affected, and did so at the early, crucial stages of the project. Valentine describes the reception as follows:

The feedback was highly positive and included comments such as, "this site can really explain any differences or controversy there can be and how to adjust" and "it could 
probably motivate some students to stick around and move ahead when they initially feel lost at MTU” (146).

Unfortunately this user testing did not continue for long, for reasons that I've been unable to determine. The website is currently the first page shown in a Google search of "Making Our Mark," as and it is a link on the homepages of the Michigan Tech Multiliteracies Center and Michigan Tech's ExSEL program. However, the site is no longer a featured, prominent link on Michigan Tech's homepage - again, for reasons undetermined - and the front page features a dubious visitor counter that makes it difficult to determine who exactly has visited the website, when, and for what purpose. At the moment, it seems that only those who are already familiar with the website know how to access it, and it is difficult to determine anything otherwise.

While it's currently difficult to determine how the project is impacting writers, coordinators, and readers, it is nonetheless necessary to investigate the usefulness of the narratives, and the ways in which the target audiences are being reached. By comparing the narratives of Making Our Mark writers that have contributed multiple years, discussing the use of Making Our Mark by coordinators, and examining a variety of responses from readers outside of the project, I hope to illuminate a few areas of Making Our Mark's effectiveness.

\section{Impact on Writers}

Unfortunately, there seems to be relatively little follow-up in terms of how Making Our Mark has affected the writers. There are, however, four authors that have "returned" some years later to write a second narrative. Comparing the first and second narrative of each author yields some interesting results, but ultimately leads to more questions than answers. 
The first returning writer wrote narratives for Making Our Mark in 2002 and 2004. In her first narrative, Norma discusses her struggle to transition from high school sports to college sports, and how her former coach gave her the confidence to succeed in both athletic and academic environments (Ceaser 2002). She then goes on to discuss how her race played in to forming a social group, remarking that finding "another black student...was like a sign that everything would be ok" but advises that being a minority in a group should not hold a student back from joining.

Her second narrative provides a rare metanarrative:

My first story was written to acknowledge the necessary tools I needed to succeed at Tech, and this story is about the result of using my "tool box" to shape my life, and how I view entering the next chapter in my life. (Ceaser 2004) The narrative goes on to discuss work ethic, job interviews, and leadership roles, with no discussion of race, class, etc. However, on the final page, Norma does something unexpected:

I was recently asked if given the opportunity again, would I choose Michigan Tech? Not to discredit any of my accomplishments...but I think my answer would be no...Michigan Tech is a great school which has developed my mind tremendously, but in reference to diversity and the human perspective, it is quite limited.

Norma goes on to say that Michigan Tech has helped her, but also takes credit for many of her own accomplishments rather than attributing success to the university. This provides an interesting contrast to her first narrative; rather than giving advice related to succeeding at Michigan Tech, Norma uses her second narrative to provide a story of success, followed by a candid opinion of the university.

The next returning writer, Madie, writes in 2004 and 2007. She opens with her first narrative with fears of the academic courses and her identity as the only Hmong student at the school, and 
continues with how she was stereotyped, singled out, and mocked (Xiong 2004). Her next section sees her explaining the actions she took in order to make her difference productive. The final section contains sober recollections that "not everything turns out the way I plan..." and that solutions "will not always end with a pleased settlement but sometimes with alternative solutions that are adjustable." Madie's next narrative comes in 2007, when writers had control over the visual design of their narrative. Madie decides to write of the "pivoting points" of her college journey: adjusting to a co-op in systems management; making friends and joining student organizations; coming to terms with Hmong identity and contributing to diversity at Michigan Tech; a letter written in response to an article in the local newspaper decrying the use of foreign flags in Houghton, and Madie's written response to it; and a page of advice for college students. Her second narrative provides an even more qualitative discussion of difference and identity than the first. Even though Madie had become more comfortable being a nontraditional student at Michigan Tech, she is still attempting to transform the mainstream by leaving complexity unsolved and challenging dominant discourses. This undoubtedly constitutes productive diversity.

In her 2006 narrative, Jill's (Olson 2006) introductory page contains the visual of a puzzle, albeit an incomplete puzzle because she is "still fitting it together". She explains the specific complications of what it means to be "local" attending a college campus; feeling "lost" in some contexts of the campus, but proud to be a representative or "guide" for mainstream students; the "strange looks" she receives for being an English Education major, and that it "doesn't help that (she) is a girl"; problems with finances; successes at jobs; and the dynamics of being one of seven children. Her feelings of being different are never (re)solved, and many issues of being a nonmainstream student remain as incomplete as the puzzle on Jill's introductory page. However, the difficulties that arise from difference are 
juxtaposed with advantages that arise from difference. In 2008, she acknowledges how her roles in life have "shifted":

I entered college as a shy, reserved high school student from a rural Michigan area who didn't know what to expect. I am leaving that same school as a confident, outgoing college graduate who knows exactly what she wants in life.

Jill discusses marriage, helping other Marking Our Mark writers, finding a better major, job hunting, struggling with courses (Olsen 2008). Her previous discussion of unresolved-yet-productive difference is eclipsed by school narrative in a way that circumvents any discussion of difference.

The fourth returning writer, Silvia, wrote in 2006 and 2009. In her first narrative Silvia begins by discussing diversity outright, and then discusses the support she found in being involved with groups which support women and Hispanic/Latinos (Espino 2006). Other sections include an in depth discussion of her family's dynamics, difficulties with classes, and social fears. Three years later, her second narrative seems to be very distanced and objective, offering a lot of advice but lacking specific difficulties discussed in the original. There is briefer mention of family difficulties and more mention of friends; there is brief mention of academic and financial difficulties, followed by a very upbeat discussion of how everything worked out perfectly; and finally, a section listing advice (Espino 2009). There is little mention of problems and no mention whatsoever of gender, race, or class.

Many commonalities exist in the comparisons of these narratives; each writer had a few years between writing their first and second narratives; each writer begins their first narrative with an explicit discussion of difference; each writer has had access to multimodal methods of narrative; and each writer writes about finding belonging and success at the university. The first two returning writers, on the other hand, treated difference in a much more direct way than the second two writers. . Norma 
does not treat difference as "resolved", but rather discusses her own self-improvement without glorifying the influences of the university. Madie seems the most willing to discuss issues of identity in her second narrative, in that she is still actively challenging dominant assumptions of difference, and treating difference as a persistent issue which requires engagement rather than something which has been corrected. Jill and Silvia, on the other hand, focus on their sense of having found a place for themselves in the university, and having overcome the prejudices and insecurities of being a nonmainstream student at a mainstream university.

Since there is no recorded history of the design choices made by the returning writers, one might arrive at one of two conclusions when examining these narratives: one possibility is that all four of the writers have achieved belonging at the university while still preserving the fact that they come from a less privileged background; the other possibility is that the earliest writer has become more attuned to the idea of productive diversity, while the others have fallen back on writing their second story in the genre of school narrative, and have become less explicit in discussing difference. Speaking as a coordinator familiar with the project but unfamiliar with these particular writers, I lean toward the second possibility. However, this only demonstrates the perception of one person on what is a very complex series of influences and choices building up into a narrative. In these cases, the coordinators who actually worked with the writers are the only ones in the position to provide the details as to why the second narratives of returning writers changed in the way they did. This is complicated by the fact that the firs returning writer, Norma, worked with the same coordinator (Valentine) for both narratives, and was only able to compose her narrative in the standardized design. The otherthreereturning writers worked with different coordinators for their first and second narratives, and had access to more multimodal methods of representation. 
One thing that can be said for these narratives is that regardless of whether or not school narrative is in place, these writers consistently provide very powerful stories about surviving Michigan Tech. In terms of demonstrating the project's early goal of providing solidarity and supporting retention, the returning writers provide some of the flagship narratives of the project. However, since the design choices of returning writers have not been recorded it is impossible to say whether or not these writers benefitted personally from the project. This is a potential area for future research that will be discussed in the Recommendations section of this paper.

\section{Impact on Coordinators}

The coordinators of Making Our Mark have produced a number of papers based on their personal involvement and academic theorizations of the project. Of the seven coordinators who have worked on Making Our Mark, three have done dissertations and two have done Master's papers relating to the project. While the website was not begun with the intention of contributing to scholarly work, it is a definite consequence of the relationships between writers and coordinators. Regarding this use of the project it is important to avoid what Cope and Kalantzis term the "white lie" - that is, the use of difference for personal academic gains, which they term "naïve (superficial) multiculturalism" (222). Kirsch and Ritchie argue convincingly that one way to avoid this imbalance is to reach a level of reciprocity where both the writer and the coordinator are learning and benefitting from the project. In fact, they argue that is the "moral obligation to assist" subjects of research, and that the researcher themselves must be transformed by the research (530-31).

Transformation of the sort described by Kirsch and Ritchie has decidedly occurred in the case of Making Our Mark's coordinators. Valentine mentions giving one of the writers a ride back to their home, partaking in food, and doing her best to negotiate discourse in a Native American household (Valentine 
166-167). Being uncertain of how to act yet conscious of what may be considered rude or polite allowed Valentine, in her words, to leave behind her "membership in dominant communities". Rather than expect the writer and her mother to adopt her own (dominant) cultural discourses, she attempts to negotiate the difference. In a similar manner, my own experiences with the project have contributed to an outlook that is much different from Michigan Tech's diversity policy. While I regard myself as at least moderately exposed to the canons of literacy and composition, I feel truly humbled by the level to which Making Our Mark has forever complicated my idea of "diversity". I also believe that this is a good thing. I find that my whiteness and maleness have been thoroughly challenged by these writers, even though I know that I can never truly understand a background or identity other than my own.

Kirsch and Ritchie meanwhile explain that researchers (in this case, coordinators) must realize their own subjectivity, as well as their positioning within this intuition. I have deleted more than a few lines from this report after realizing that I have no right to speak for Making Our Mark's writers, and that I cannot pull "the God trick" in order to arrive at a definite conclusion of anything. Kirsch and Ritchie remind me, thankfully, that partial understanding can be a good thing. Valentine, Springsteen and myself, as members of the mainstream, have all benefited from our interactions with underrepresented writers, and have been made aware of our positioning as white university instructors.

While there was some idea from the start that Making Our Mark would be of some benefit to the coordinators, there is no doubt that this has become one of the most noticeable examples of productive diversity. It is important that we recognize this use of the project, but also prevent use for selfish or purely academic purposes. 


\section{Impact on Mainstream Users}

While the founders of Making Our Mark identified two primary audiences - students from underrepresented backgrounds and teachers/faculty - the disruption of mainstream stereotypes was not just a consideration. Rather, it was something inherent in the goal of productive diversity. So, as the websites have encountered various users and audiences from the mainstream, there have been a number of unanticipated interactions. As private lives are made public, a number of issues arise, including a backlash from mainstream (and non-mainstream) individuals toward institutional diversity. Since many institutions foreground diversity in order to achieve profit and dominance, some perceive public discussions of diversity as "cynical, manipulative, invasive, and exploitative" (New London Group 16-17) Accordingly, viewers of Making Our Mark may perceive the project as nothing more than another example of superficial multiculturalism. Early coordinators and writers assumed that the project "would be of interest to students and perhaps professors and instructors but of little interest to administrators," and similarly warns of the reification involved in giving control of the narratives to the university (Valentine 172-175).

This specific type of use by a mainstream audience is showcased in attempts by the university to use Making Our Mark as a marketing tool to recruit students. In 2002 the student recruitment office requested ("offered") to create brochures based on the website (Valentine 174). There were no permissions from the writers to do this, and the coordinators felt that it would not coincide with the individual purpose of the project. Springsteen voices an additional concern that Michigan Tech paid no attention to the actual "struggle, power, conflict, and threat" discussed in the narratives, and instead saw the websites through the lens of superficial multiculturalism (30-32) 
This type of use would add a dimension to the project that was not initially considered, and which does not factor into the project's ultimate goal of productive diversity. It serves dominant institutional interests in terms of trying to increase the numbers of underrepresented students on campus, but does not make any attempts to explain why these types of diversity are important, or explain the ways that "diversity" can be something besides a goal in and of itself. Finally, if the university were to translate the websites into brochures, the control over the narratives would shift to higher administrative levels of the university. It would be safe to say the narratives that most actively challenged dominant assumptions of race, gender, class, etc., would be ignored, watered down or censored entirely in order to protect the university's private interests. When the university administration began examining the narratives in terms of marketing tools, concerns were expressed with regards to how the successes or failures of students represented Michigan Tech as a university. This was accompanied with complaints that the website did not show the success of students from mainstream backgrounds (Valentine 176-177). At this point of co-option, any level of productive diversity would be quickly reduced to superficial multiculturalism.

On the other hand, there have been a number of less than positive responses from outside audiences. Whereas Michigan Tech's administration wanted to use Making Our Mark as a potential marketing tool, mainstream audiences have assumed that it already is a marketing tool. Former coordinator Jill Hodges writes of the response of a white male Michigan Tech alumnus. In 2004 the gentleman, known as Lubowicki, wrote an email to the director of the Michigan Tech Writing Center, and a letter to the editor of a local newspaper, explaining why the Making Our Mark narratives were not appropriate. He vehemently "couldn't care less that (a writer) is half Puerto Rican and half White-it doesn't matter" (6). This reaction is complicated by the fact that Lubowicki perceives Making Our Mark 
as something produced by the marketing department and/or administration of the university. Hodges maintains that this misunderstanding is because the narratives are contained within "institutional space" (Hodges 6-15). Lubowicki's attitude is the result of the project being used by an audience that does not seem to have been initially considered. It is also a result of a misinterpretation of the original purpose of the project. It is not clear how he became exposed to Making Our Mark, but it is clear that he read through the narratives without being aware of their context.

Lubowicki was quite upset over a number of things, one being the fact that difference and race is being discussed outright (specifically in terms of identity labels). The reception of Making Our Mark by mainstream viewers, Hodges argues, disrupts the "colorblindness" of those who have never had to struggle because of their identities (Hodges 9-10). Valentine supports this by saying that Making Our Mark challenges the "investment in whiteness" by mainstream audiences (Valentine 141-142). It is much easier for a member of the mainstream to ignore issues related to identity, since those of mainstream backgrounds "never have to address issues of identification" (Hodges 10) and more easily navigate our dominant institutions. This sentiment is echoed in a response letter to Lubowicki:

As Matt Hill stated in his response to Lubowicki, he admits that he had the privilege of being able to think that race does not matter due to the fact that he was a white male from an affluent background (Hodges 8).

What is significant here, aside from the polarized reactions of Lubowicki and Hill, is the fact that Making Our Mark has created a very substantial dialogue outside of the website.

The writers of Making Our Mark are well aware of these mainstream responses to overt difference. This is made clear in many of the narratives, but perhaps illustrated the best when Madie responds to the "absurd, xenophobic statements" made by a community member who wrote the local 
newspaper to decry the flying of "foreign" flags during Parade of Nations (Xiong 2007). While said community member was responding to difference as presented in Houghton's "Parade of Nations" and not the Making Our Mark narratives, this exchange is showcased within Making Our Mark. I bring up Madie's example to showcase that the greatest impacts of Making Our Mark on the mainstream takes place not only when whiteness and racelessness are disrupted, but when these disruptions are transcribed and discussed as well. By challenging whiteness, and therefore asserting productive diversity, it is creating room for an actual conversation with those who are disillusioned by attempts to use diversity as a recruitment tool. In essence Lubowicki's response to Making Our Mark is an argument against productive diversity; however, it is more strongly an argument leveled against the prevalence of superficial multiculturalism in our institutions. If the writers of Making Our Mark are able to engage an audience like Lubowicki in dialogue, there is an opportunity to learn, mainstream audiences can indeed change their perceptions of (institutional) difference.

This capacity to change the mainstream is one of the most significant ways of establishing productive diversity over superficial multiculturalism. However, Making Our Mark will only be successful in affecting mainstream audiences if two things happen. Obviously, the project must avoid being coopted for marketing purposes. However, equally important is that outside audiences do not perceive Making Our Mark as a product of superficial multiculturalism. 


\section{Recommendations}

Given the tensions I've outlined, I would like to propose a number of steps that would help sustain Making Our Mark in terms of reaching its goals. The most important of these changes would be a widespread use of the project as a learning tool in academic contexts. However, this change would suddenly bring the project into contact with many new audiences, so I argue that it cannot happen until three other steps are taken with the project:

- Subjects such as race, gender, class, age, etc. must be problematized so that the narratives are truly engaging the topic of difference rather than simply perpetuating school narrative

- Design choices must be documented so that changes made are always justified in terms of Making Our Mark's original goals.

- The project must be user tested in order to gauge the impact on outside audiences. Meanwhile, past writers and coordinators should be interviewed to ensure that reciprocity has occurred Each of these items aims to safeguard Making Our Mark from misinterpretation or misuse that may arise from the tensions I've identified in previous sections. Only after this is done can the project begin a more progressive move of becoming a more widely-used learning tool.

\section{Encourage Complication of Difference}

For starters, narratives need to move back to a more explicit discussion of difference. The labels in the 2002-2006 narratives were one way of doing this. However, they could be considered reductionist (Kirsch \& Ritchie), and in some cases caused mainstream audiences to perceive Making Our Mark as a marketing tool (Hodges 6). However, with the current lack of labels, some of the narratives don't make 
difference explicit enough to actually challenge the mainstream - these narratives could just as well have been written by mainstream students going through very common struggles in the university.

It is a rare case that we have an actual record regarding a response to Making Our Mark. In the case of Lubowicki, we have a rather heated reaction from "the mainstream," specifically a Michigan Tech alumnus who voiced out against identity labels, and ultimately the project in general. The fact that a more direct approach to difference garnered this strong of a reaction says that Making Our Mark should encourage features and stories that directly challenge dominant paradigms. If it is making the mainstream uncomfortable by challenging racelessness, genderlessness or any other "-lessness," it means that the narrative are at least creating a dialogue. As spectacular as the visual designs of Making Our Mark have become, no one is writing in to the local newspapers complaining about them. On the other hand, it is very easy to picture the university using the more recent narratives as marketing brochures. They represent diversity in a stylish way, but not in a way that would cause a stir.

I argue that bringing back some level of inscription is necessary. Obviously it must be balanced, with enough inscriptions to challenge "whiteness," but not enough to subdue narrative or reduce complexity. Therefore, the trend to avoid discussions of difference must be removed from the project. To accomplish this, the coordinators must explicitly foreground the purpose of the project, and do so in their early meetings with writers. The coordinators can accomplish this in a number of ways:

- Identifying the goals and audiences of the project as laid out in its early stages

- Explaining to the writers why they were solicited to take part in the project

- Defining terms such as "productive diversity" and "superficial multiculturalism" 
Ideally, this would allow writers to compose authentic and emotionally charged narratives that connect with Making Our Mark's audiences; this would also work to ensure the audiences are impacted in ways that achieve productive diversity.

An additional improvement that could be made would be to change the Making Our Mark website to a blog-type format. This would accomplish a number of things for the writers. First, it would give them direct control over the creation of the website itself, and in turn the coordinators would be able to focus on foregrounding the project and aiding the writers in their compositions. Secondly, since many of the younger writers have come of age during Web $2.0^{5}$, a blog format could be more familiar than static websites. This isn't to say that all writers have had historical access to Web 2.0 technology, but rather that utilizing a more democratic version of website might reduce the perception of coordinators as "gatekeepers", and in turn reduce school narrative.

\section{Document Design Choices}

The implementation of multimodality, combined with the changes in coordination, seems to have had a profound effect on many aspects of the narratives. Revisiting Tables 2, 3 and 4, we can see a direct correlation between the switching out of coordinators and the major changes in the creation and design of the narratives. These changes are being made even though there is little record as to why certain design choices were made by a coordinator, or why these choices were changed or discontinued by other coordinators.

\footnotetext{
${ }^{5}$ By Web 2.0, I am referring to the changing nature of the internet which provides for more widespread implementation of user-generated content and interactivity.
} 
One example of this is the previously mentioned identity labels in the 2002-2006 narratives. On one hand, the case of Hodges recording the design choice behind the identity labels allows us to examine the choice, and bring it into dialogue with theorists such as Michaels and Sohmer. On the other hand, it's difficult to determine why a 2006 writer chose to omit her label, and why this became a design choice that was extended to all narratives after 2006. In this case, the coordinator could provide the insight needed to better examine this design choice in the wider context of the project.

While this example is a noticeable feature of the overall project, there are nonetheless several less noticeable but equally important features that have not been kept up between coordinators of the project. For example, there is a link at the bottom of each year's homepage linking to "Resources" for Students and Faculty. Of the eight resources for students, only two are still functional. This is not the result of any sort of conscious decision to change the website; it is a section of the project that has been pushed to the side and neglected to the point of it no longer being relevant. Should the coordinator(s) choose to update this, it would be important for them to know what the original function of this page was. Should all of these links be updated? Should more links be added? Should others be removed? The "why" involved in this particular section has been lost, and this page has fallen into obsolescence. If this project is to continue, there has to exist some sort of documentation for adding, sustaining and removing components of the website.

In short, any future design choices made in Making Our Mark must be recorded and evaluated in terms of how they are contributing to productive diversity. In particular, years when there is no overlap between new coordinators (such as 2003 and 2008) or years when there are significant changes being made to the overall project (2005 and 2008) should have some sort of record. This task ultimately falls on the coordinator, but ensures that the design choices made will be available for consideration by 
future coordinators. While it could be difficult to reclaim the design choices made in previous years, there is still the opportunity to follow up with previous coordinators of the projects. Interviews with those who have worked on the project would likely provide stories and information that is not found in their respective publications.

\section{Test Effectiveness}

There has been a lack of assessment of Making Our Mark in terms of impact. One quick way of testing the impact of the project extends back to its very first audience: first year students in the Michigan Tech Writing Center who were asked to view and evaluate the website before it was made available on the internet. It is doubtless that the nature of websites, attitudes towards difference, and student demographics at Michigan Tech have changed over the last decade. Nonetheless, first-year students still comprise one of the audiences of Making Our Mark. It would be to the advantage of the project to begin a tradition of user-testing. Aside from seeing how mainstream and non-mainstream students respond to the project, this has the secondary advantage of making the project more visible to students who might benefit from the narratives.

As mentioned above, Valentine describes the early user-testing of Making Our Mark as successful, since it illustrated reactions from one of the project's target audiences (146). In particular, these students were asked if the site was "useful", which narratives they connected with, and whether or not they would recommend the website. Since the feedback sheets are likely not available any longer, it is hard to determine how close this testing was to true "usability testing" as opposed to students giving their opinion about the perceived effectiveness of the narratives. The intended use of the website is supposed to be support and advice. Because of this, the emotional response of the 
audience is extremely relevant, especially now that the visual designs of the narratives changed so much. ${ }^{6}$

Another way to determine how much impact the project has would be to conduct follow-up interviews with the previous writers and coordinators of the project. While we've seen that coordinators have benefited from the project in numerous ways, we need to know if the writers themselves are benefitting. As mentioned, it is difficult to gauge how the writers are benefitting from the project. One possible approach to this would be to examine Making Our Mark in conjunction with other sets of university narratives (departmental profiles, study abroad narratives, etc.). This could provide a benchmark to determine whether Making Our Mark's narratives are discussing challenges and difference in a way that is a departure from "school narratives". A second approach, and perhaps one more keeping within the style of Making Our Mark, would be to ask previous writers to compose a metanarrative regarding how their perceptions of difference has been changed from working on the project.

If the effects on the writers cannot be determined, Making Our Mark is unable to ensure reciprocity between writers and coordinators. If the website becomes nothing more than a series of research opportunities for graduate students, it has become one more monument to superficial multiculturalism. On the other hand, exploration of this reciprocity might explain whether or not the school narrative present within Making Our Mark's stories is due to the writer/coordinator relationship,

\footnotetext{
${ }^{6}$ While a heavy discussion of usability and technical communication extends beyond the scope of this paper, it is worthwhile to mention that Donald Norman argues that emotions and aesthetics play as great a role as cognition in terms of usability design, and are "crucial for everyday decision making" (8).
} 
or due to more widespread influences such as post-racism or Graff's "literacy myth". Regardless of how sensitive the coordinators are to the backgrounds of students, coordinators of mainstream backgrounds run the risk of being received as part of the efforts to co-opt the students' identities in the name of superficial multiculturalism. Whether or not this is already happening should be analyzed in order to ensure an effective continuation of the project.

\section{Implement Project for Teaching}

As I've mentioned, the use of Making Our Mark as a type of outreach tool has several complications, the most essential of which is that any institutional outreach will contribute to or become associated with superficial multiculturalism. Nevertheless, Making Our Mark provides an underutilized opportunity for coaches, instructors and faculty to expand their experience with difference. First of all, coaches in Michigan Tech's numerous learning centers encounter students of non-traditional background on a regular basis. This might be in regards to such surface-level concerns as formulas or grammar conventions, or much higher level concerns such as the cultural expectations of the institution. Nonetheless, familiarity with the stories presented on Making Our Mark could serve to dispel stereotypes while exploding the range of challenges that underrepresented students encounter. Not only would this be a learning experience for the coaches, but it would also provide one more level of support for the underrepresented student, many of who credit learning centers as part of their success at the university.

Secondly, university instructors of common first-year and university-wide courses could implement the project as a way to improve their teaching. While many of the writers have expressed finding a place in the university after a few semesters, an overwhelming majority of Making Our Mark writers have expressed having difficulty in their first and second years in particular. If the instructors 
who teach these crucial first classes were more aware of what difference really means - outside of recruitment statistics and stereotypes - they would be in a unique position to revise their pedagogy in a way that could level the playing field between students of privileged and non-privileged backgrounds. Incorporating Making Our Mark as a more widely used resource for coaches and instructors would open the door for two types of productive diversity first espoused in Making Our Mark's goals: increasing the retention of students, and making an impact on the institution.

\section{Conclusion}

Bringing back more explicit discussions of difference, documenting the reasoning behind changes to the project, and assessing the impact of Making Our Mark are actions that must be taken by the coordinators of Making Our Mark in conjunction with others both inside and outside the project. Any one of these three actions is an immense undertaking in itself, and it is only after these three requirements are satisfied that one should begin the work of implementing the project as a learning tool. Each of these recommendations in themselves is meant to improve the overall state of Making Our Mark, but they are ultimately meant form a scaffolding for a much more profound change in regard to how the project is used by its audiences. Ultimately, however Making Our Mark is currently being written, designed, or used, it provides immense potential to extend discussions of difference in highly constructive ways, with the possibility of creating change in both mainstream and non-mainstream environments alike. 


\section{References}

Barron, Nancy. "Ya Vez Como Son?/You See How They Are?": An Investigation of Cultural and Social Assumptions that Undermine Literacy Education. Dissertation, Michigan Technological University, 2001

Blackmon, Samantha. “(Cyber)Conspiracy Theories: African-American Students in the Computerized Writing Environment." Labor, Writing Technologies, and the Shaping of Composition in the Academy. Ed. Pamela Takayoshi and Patricia Sullivan. Cresskill, NJ: Hampton, 2007.

Brodkey, Linda. "On The Subject of Class and Gender in 'The Literacy Letters." Cross-Talk in Comp Theory. Ed. Victor Villanueva. 2003. pp 677-696

Cope, Bill and Mary Kalantzis. "Introduction - Multiliteracies: the beginnings of an idea." Multiliteracies: Literacy Learning and the Design of Social Futures. Ed. Bill Cope and Mary Kalantzis. London: Routledge, 2000. 3-8.

Graff, Harvey J. "The Nineteenth-Century Origins of Our Times." Literacy: a Critical Sourcebook. Ed. Cushman, Ellen. Boston: Bedford/St. Martin's, 2001. 211-233.

Hodges, Jill. “Making Our Mark @ MTU: An Analysis of Unexpected Audience Response”. Coursework paper, Michigan Technological University, 2005.

Kalantzis, Mary and Bill Cope. "Changing the Role of Schools." Multiliteracies: Literacy Learning and the Design of Social Futures. Ed. Bill Cope and Mary Kalantzis. London: Routledge, 2000. 121-148.

Kirsch, Gesa E., and Joy S. Ritchie. "Beyond the Personal: Theorizing a Politics of Location in Composition Research." Cross-talk in Comp Theory: a Reader. Ed. Villanueva, Victor. Urbana, IL: National Council of Teachers of English, 1997. 523-546. 
Kress, Gunther. "Multimodality." Multiliteracies: Literacy Learning and the Design of Social Futures. Ed. Bill Cope and Mary Kalantzis. London: Routledge, 2000. 179-200.

Making Our Mark @ MTU. 2002-2010. Retrieved 2011. <http://www.hu.mtu.edu/makingourmark/> Michaels, Sarah and Richard Sohmer. "Narratives and Inscriptions." Multiliteracies: Literacy Learning and the Design of Social Futures. Ed. Bill Cope and Mary Kalantzis. London: Routledge, 2000. 267288.

New London Group, The. "A Pedagogy of Multiliteracies - Designing social futures." Multiliteracies: Literacy Learning and the Design of Social Futures. Ed. Bill Cope and Mary Kalantzis. London: Routledge, 2000. 9-39.

Norman, Donald. "Prologue: Three Teapots." Emotional Design: Why We Love (or Hate) Everyday Things. New York: Basic Books, 2004. 1-11.Springsteen, Karen. Approaches to Diversity: Multimodality and Representational Ethics in Making Our Mark. Dissertation, Michigan Technological University, 2008.

University Marketing and Communications. "University Web Policy". Michigan Technological University, 2007. Retrieved 6- 10-2011 from http://www.admin.mtu.edu/admin/policy/gen/1005.htm Valentine, Kathryn M. Uncertain Respect: Literacy Practices, Identity Negotiations, and the Teaching of Composition. Dissertation, Michigan Technological University, 2003.

Villanueva, Victor. "On the Rhetoric and Precedents of Racism." Cross-talk in Comp Theory: a Reader. Ed. Villanueva, Victor. Urbana, IL: National Council of Teachers of English, 1997. 829-845. 